\title{
UNA CRISTOLOGÍA CON PERSPECTIVA HISTÓRICA Y EXPERIENCIAL
}

\section{A Christology with a Historical and Experiential PerspectiveThe Philosophy of Immanuel Kant}

\author{
Paola Polo Medina \\ Universidad Femenina Sagrado Corazón.paolaplom@unife.edu.pe \\ ID ORCID: 0000-0002-7782-0491
}

\begin{abstract}
RESUMEN
El presente artículo pretende acercarnos a una lectura sencilla y comprensible de la necesidad de abordar la temática cristológica, la fe en la divinidad de Jesús, desde la perspectiva histórica y la experiencia humana. El punto de partida es la convicción de que la cristología puede ser mejor comprendida si la divinidad de Jesús se lee desde la historia y no fuera de la historia. Si está transida por la experiencia humana de quienes le conocieron y descubrieron en la vida misma su divinidad. Así mismo, de este modo nos alejamos de las posturas docetas que hoy en día siguen afirmando que no es necesaria la experiencia histórica, dejándonos de este modo un Jesucristo muy lejano y abstracto, que es poco comprensible y en tanto poco creíble para nuestros tiempos.
\end{abstract}

\section{Palabras clave:}

Cristología, divinidad, humanidad, experiencia, perspectiva histórica, Jesús histórico, Jesucristo.

\begin{abstract}
This paper aims to bring us closer to a simple and understandable reading of the need to approach the Christological theme, faith in the divinity of Jesus, from the historical perspective and the human experience. The starting point is the conviction that Christology can be better understood if the divinity of Jesus is read from history and not from history. If it is affected by the human experience of those who knew him and discovered his divinity in life itself. Likewise, in this way we move away from the twisted positions that today continue to affirm that historical experience is not necessary, thus leaving us a very distant and abstract Jesus Christ, who is little understandable and as little credible for our times.
\end{abstract}

\section{Keywords:}

Christology, divinity, humanity, experience, historical perspective, historical Jesus, Jesus Christ. 


\section{INTRODUCCIÓN}

La historia de la cristología, desde sus inicios, ha estado relacionada a la interrelación establecida entre la interpelación de Jesús y los intereses humanos por la salvación (Vitoria, 1986). Esto responde a que la cristología es un discurso siempre abierto, donde Cristo no es el objeto de una ciencia sino el sujeto que nos interpela (González, 1984) $\mathrm{y}$ ante quien podemos acercarnos con nuestras inquietudes e intereses (Segundo, 1982). Dicho al modo de los Evangelios, la cristología se enmarca en dos claves. Una primera está expresada en quienes se acercan a Jesús con la pregunta: "¿eres tú el que ha de venir, o debemos esperar a otro?" (Mt 11,3) y la otra clave se hace visible en la experiencia de quienes se sienten interpelados por el Jesús que pregunta: "Y vosotros ¿quién decís que soy yo?" (Mt 16,15). Dos planteamientos que han hecho de la cristología, desde los primeros años del cristianismo, un discurso vivo tal y como lo expresa E. A. Johnson (2003):

Como el cristianismo del siglo I, también hoy estamos llamados, los hombres y mujeres, a escribir la buena noticia en un lenguaje adecuado a nuestras circunstancias de tiempo y lugar. Al igual que las primeras comunidades, somos un discipulado vivo y tenemos que tratar de realizar la tarea nunca acabada de confesar a Jesucristo en una Iglesia peregrina. Desde nuestra propia experiencia de salvación, desde nuestra narración de la historia, desde nuestra praxis y nuestra oración, tenemos que encontrar nuevos nombres para Cristo y reivindicarlo para nuestro pueblo, con el fin de transmitir una cristología viva a la próxima generación.
Ambas cuestiones cristológicas no tienen valor en sí mismas si no se las contextualiza en el entorno cultural y temporal de la vida judía del siglo I y la expectativa salvífica que tenían. Pero, ya que la perspectiva soteriológica se va a mantener a lo largo de la historia, se ha de comprender y recomprender en cada tiempo según los elementos que la condicionan. Por ejemplo, la expectativa salvífica de los oyentes de Pablo no fue la misma que la salvación que esperaban los seguidores de Jesús ni es la misma que hoy reclama el cristianismo y la que reclaman las mujeres hoy. Teniendo en cuenta esto, vamos a centrarnos en tres momentos claves dentro del devenir de la cristología: la cristología testamentaria canónica, la conciliar y la del siglo XX. Veremos cómo ha ido cambiando el horizonte soteriológico y sus causas; y nos fijaremos en la necesidad de un discurso cristológico inclusivo, histórico y actualizable desde la experiencia.

Empezaremos por el Testamento Cristiano para ver en qué sentido se dice que en Jesús de Nazaret estaba actuando Dios a nuestro favor. Luego, nos fijaremos en cómo en la cristología de los concilios, desde un carácter apologético, se llega a definir propiamente la divinidad de Jesús alejándose del Testamento Cristiano. Esta fase es importante porque lo que se define en estos concilios sobre la divinidad de Jesús, ya no se moverá hasta el siglo XX, marcando durante mucho tiempo la vida cristiana y la praxis. Enseguida, ahondaremos en la cristología del siglo XX: su diálogo renovador y su giro en la interpretación de la divinidad de Jesús, permitiendo el emerger de las teologías contextuales (Márquez, 2010). En este recorrido es importante no perder de vista el papel de la experiencia humana como herramienta teológica, la función que ejerce la expectativa salvífica dentro de la 
historia de la humanidad y la perspectiva histórica en la interpretación de Jesús. Así mismo, hay que fijarnos en cómo las preguntas cristológicas se inculturizan exigiendo nuevas respuestas, acordes a los nuevos tiempos. Nuestro objetivo es afirmar la necesidad de una cristología con historia, con experiencia, contextual, plural, abierta e inclusiva. Por esta razón, no hacemos un recorrido exhaustivo por toda la historia de la cristología. Nos avocamos al discurso experiencialhistórico, presente ya en la cristología primera y recuperada en las teologías del siglo XX.

\section{Las cristologías del Testamento Cristiano}

Dentro de las cristologías del Testamento Cristiano canónico vamos a centrarnos en aquella que se desarrolla en torno a los intereses de los oyentes de Jesús y los de Pablo. El cambio de uno a otro está marcado por el horizonte salvífico. Esta transformación nos confirma que las cristologías se articulan inevitablemente desde los condicionamientos históricos, sociales y culturales en los que están insertos quienes experimentan la fe. En este sentido, hay que admitir la relevancia que tiene la experiencia humana al articular el discurso teológico. Veamos pues, a grandes rasgos, estas cristologías.

\section{Los oyentes de Jesús: el anhelo del Reino de Dios y la espera del Mesías}

En tiempos de Jesús, la expectativa salvífica se centraba en el establecimiento del Reino de Dios (Vitoria, 1986) y la espera de un Mesías que implantaría ese Reino de justicia. Esto se percibe claramente en la pregunta a Jesús "¿eres tú el que ha de venir, o debemos esperar a otro?" Ante esta cuestión, la propuesta de Jesús del
Reino confirma la expectativa mesiánica transformándola. Esta transformación se ve explicitada en la respuesta de Jesús: "Id y contad a Juan lo que oís y veis: los ciegos ven y los cojos andan, los leprosos quedan limpios y los sordos oyen, los muertos resucitan y se anuncia a los pobres la Buena Nueva" (Mt 11,4). Es decir, el Dios revelado en Jesús con sus obras y palabras no es solamente un Dios compasivo, sino un Dios que lucha contra la instrumentalización de la ley religiosa que es usada para oprimir al pueblo (Segundo, 1982). Por esta razón, ya que en Jesús la gente vio cumplida las expectativas salvíficas de Dios, tras la experiencia de la Resurrección le presentan como el Mesías. Esto no es otra cosa que la fusión de experiencia e historia como eje fundamental de la narración donde queda reflejado "lo que un tal Jesús significó para la vida de algunos grupos (Schillebeeckx, 1981, pág. 38). Una experiencia histórica rememorada que llega a su culmen con la experiencia histórica del Resucitado (Hurtado, 2013).

La experiencia del Resucitado hay que ubicarla dentro de su contexto. Tras la muerte brutal de Jesús, comprendida como injusta, la gente intentó buscar explicaciones a lo que le había pasado a Jesús. Los interrogantes que afloran, y que irán adquiriendo poco a poco un sentido salutífero y escatológico, es lo que hizo posible creer en la resurrección de Jesús y su salvación (Moingt, 1995): El Jesús que habían conocido en Nazaret no podía quedar clavado en una cruz y condenado al olvido. Todas estas experiencias sentidas, además de suscitar la pregunta de por qué a Jesús le crucifican, inducen a abordar el tema de la muerte de Jesús, poniendo también la mirada en la pasión y en la vida pública. De este modo, la muerte de Jesús -más que como rechazo de Dios- se expresa como aceptada por Dios en consideración a nosotros (Mc 8,31; 10,33-34; Mt 16,21; 
Lc 9,$22 ; 19,32 ; 24,25-27.44-46)$ y que por eso Dios le resucitó (Hch 2,23-24; 3, 13-15; $4,10-11 ; 17,2-3)$. Puesto que no era fácil conciliar la imagen de un resucitado con la de un crucificado, tuvieron que interpretar la cruz como servicio y humillación (Mt 20,25-28; Mc 10,42-45; Lc 22,24-27; In 13,12-17). Con esto, Jesús adquiría una nueva identidad: como el Señor y Salvador. Y se agrega un matiz a la perspectiva salutífera de la muerte de Jesús: Jesús ya no es visto como un Salvador pasivo, sino que es coautor de la salvación de Dios (Jn 3, 14; 8,28; 12,32) (Moingt, 1995).

La vuelta a la pasión permitió ver que la cruz de Jesús era el resultado de una forma de vida concreta. Esto los llevó a poner la mirada en la vida pública de Jesús, con la que intentarán responder a las cuestiones cristológicas. Habían comprendido, desde muy pronto, que el Resucitado es el Crucificado Jesús de Nazaret y que, por eso, había que tener en cuenta la historicidad de su vida (Moingt, 1995) (Käsemann, 1978) para justificar lo que le había pasado y cómo en él Dios se había acercado y nos estaba salvando. Es decir, la experiencia del Resucitado y la memoria reciente de la muerte de Jesús los lleva a rememorar su vida histórica. Es aquí, en este punto, donde la experiencia histórica y la memoria tienen vital importancia para la relectura de Jesucristo. Ello permite unir al Resucitado con Cristo y con Jesús de Nazaret.

La vuelta a Jesús de Nazaret, a través de las preguntas cristológicas, desveló que en sus obras y enseñanzas se habían hecho presentes los signos del Reino que tanto esperaban, la liberación de Dios. Es decir, Jesús era alguien que mostraba las maravillas del Reino a través de su cercanía fraternal y sororal, pero también desde el desvelamiento de la opresión y la oposición a los opresores. De aquí que en los evangelios, Jesús sea narrado como aquel que toca a enfermos y los cura, que devuelve la vida y dignidad a los pobres, que se acerca y habla con mujeres, que se deja tocar por ellas y por los enfermos, que acoge a prostitutas y a niños, que se sienta a la mesa con publicanos y pecadores, que habla con autoridad, que valora la acción de la viuda pobre que lo da todo y que se enfrenta con las autoridades en defensa de la vida. Todo esto era visto como Buena Noticia de salvación pues en ello veían vislumbrarse la relación no solamente de Jesús con Dios (su divinidad) sino también la relación de Dios con la humanidad (nuestra salvación); es decir, nuestra propia dignidad humana. Esto era posible porque el Reino expresado en la práctica de Jesús permite que el acceso a Dios salga de la vía de lo sagrado, al que no todos podían llegar, y se abra paso por la vía profana del estar con el otro en la propia historia. Ya no por medio de sacrificios y cumplimiento de la Ley sino en la solidaridad con las otras personas.

Este cambio de perspectiva en la comprensión de Jesús de Nazaret, es lo que permitió que a Jesús se le atribuyeran -con el tiempo- los títulos de honor que expresan que en Jesús habían visto a Dios: profeta, exorcista y curador de mucha fama, maestro, Mesías, Hijo de Dios, hijo del hombre (Segundo, 1982) (Theissen, 2009) (Barbaglio, 2009). En este sentido, los títulos son fruto de la experiencia cercana de aquellos que han seguido a Jesús. Dicho con otras palabras, en los evangelios quedará expresada una "divinidad" desde la humanidad histórica. Es en la vida histórica de Jesús donde la gente percibió la acción salvadora de Dios y la experiencia la que lo atestigua y lo nombra. Más que una divinidad reflexionada y argumentada, en él vieron a un Dios experienciado históricamente: a un Dios que podían ver, escuchar, cuestionar, etc. 


\section{Los oyentes de Pablo. La salvación como justificación}

Aunque la interpretación que Pablo hace de Jesús dista de la muerte del Nazareno unos treinta años, entre los relatos de los sinópticos y la interpretación paulina parece haber transcurrido mucho más tiempo. Si bien la causa puede estar en el hecho de que cuando Pablo escribió no conocía aún los relatos evangélicos en su totalidad y el que Pablo responda a problemas particulares de las comunidades (Segundo, 1982), hay que considerar también que se produjo un cambio en el horizonte salvífico. Un cambio condicionado por la presencia de cristianos venidos del judaísmo y otros del paganismo. Es decir, hay que pensar que Pablo tuvo que agenciárselas para ver cómo podía hablar de Jesús a los paganos quienes no esperaban al Mesías ni el Reino. Veamos un poco más en detalle.

Al retrasarse la parusía, la inminente y definitiva llegada del Reino y el Mesías ya no dicen nada a los oyentes de Pablo. Ahora esperan la salvación como justificación, y la respuesta paulina la confirma, pero transformándola desde los requerimientos históricos actuales (Segundo, 1982) (Segundo, 1991). Es decir, la salvación se ve proyectada como la liberación del pecado que tiene que ver con la injusticia del mundo (Rom 1,16-32). Se trata, por tanto, "de justificar desde lo divino, las relaciones deshumanizadas". De esta forma, se ha pasado de la denuncia concreta de la opresión (en tiempo de Jesús) a la acusación más general de las relaciones sociales desprovistas de verdad y humanidad (Segundo, 1982). Se ha pasado de una clave política del Reino a una clave antropológica que es más comprensible al pueblo pagano y que está con relación a su lucha contra la infrahumanidad que deviene del Pecado.

En suma, en el Testamento Cristiano, la predicación de Jesucristo se enmarca en el plano soteriológico y no en el de las especulaciones helenísticas o concepciones esencialistas que son posteriores. La predicación de Jesucristo tiene su Sitz im Leben en la expectativa cristiana de salvación que se ve cumplida en el Jesús de Nazaret. Por su parte, en Pablo se concretará en la muerte y resurrección de Jesús por la que nos ha constituido como hijos de Dios, librándonos de lo inhumano. Es, dicho brevemente, una cristología de corte histórico y experiencial que recoge el presente y lo relee desde la experiencia acontecida en el pasado, aunque no muy lejano.

\section{La cristología conciliar}

Aunque los dogmas cristológicos sean poco comprensibles hoy, no se pueden obviar. Ellos contienen la doctrina acerca de Jesucristo que ha marcado profundamente la historia de la teología y la vida cristiana. Una vez establecido el dogma acerca de Jesucristo, la teología se dedicó únicamente a explicar, precisar y enriquecer las formulaciones. Por eso, es necesario conocer lo que dice Nicea, Constantinopla I (s. IV), Éfeso y Calcedonia (s. V) ${ }^{1}$ acerca de Jesús y nuestra salvación; y cómo se llega a la confesión de fe en él, qué elementos la generan y condicionan y cuál es el contexto cultural que las envuelve ${ }^{2}$.

\section{El carácter soteriológico}

La cristología conciliar también intenta dar razón de la fe en Jesucristo. De hecho,

1 No mencionamos Constantinopla II y III (siglos VI y VII), pues, aunque contienen un gran desarrollo teológico posterior, no aportan definiciones cristológicas propiamente dichas.

2 Previo a la enunciación de los dogmas cristológicos hay dos siglos de debates (II - III d.C.) centrados en la relación de Jesús y Dios y en la defensa del monoteísmo cristiano. 
en los diálogos y debates que le preceden y la motivan, están vigentes las preguntas cristológicas sobre si Jesús era el que debía venir con la salvación de Dios (Sesboüe, 1995). Sin embargo, entre la narración bíblica y la interpretación dogmática de los concilios hay un abismo producido por el paso de una confesión de fe experiencial centrada en la praxis histórica de Jesús, a una fe metafísica centrada en la esencia de su ser. Si los Evangelios y Pablo estaban interesados en la relación de Jesús con Dios desde la humanidad concreta e histórica y cómo en ello se daba la salvación de la humanidad, a partir de los concilios se introducirá una cristología con carácter apologético y una noción metafísica. La respuesta cristológica ha cambiado porque ha cambiado la realidad y la experiencia sobre ella.

El cambio responde a la expectativa salvífica del momento y el contexto que condiciona y configura el desarrollo del discurso. En esta época, el horizonte salvífico ya no está marcado por el Reino ni por la justificación. Debido al contexto cultural griego, la salvación se espera ahora como divinización. Puesto que lo que no es divino se considera caduco, con el alcance de la divinización se espera la vida para siempre, la salvación. Así, la respuesta de la Iglesia fue la afirmación de la condición divina de Jesús. Era necesario, puesto que nadie puede dar lo que no tiene. Así, para afirmar nuestra salvación (divinización) había que afirmar la divinidad de Jesús, ya que si Jesús no es Dios no puede salvar.

\section{El carácter apologético de los concilios}

Tras el encuentro con la cultura griega, la teología se va a servir de categorías griegas. Tuvo que elegir entre quedarse con la figura excepcional de Jesús o afirmar rotundamente su divinidad. Eso le supuso presentar un discurso distinto de terminología antagónica: Dios y hombre, consustancial al Padre y consustancial (Sesboüe, 1995) al ser humano, perfecto Dios y perfecto hombre, hijo de Dios y hermano de los hombres (Vitoria, 1986). El interés subyacía en la salvaguarda de nuestra salvación ante quienes negaban la divinidad de Jesús. Por eso, Nicea (s. IV. 325 d.C.) y Constantinopla (381 d.C.) tras afirmar que Jesús es Dios en cuanto Logos e Hijo de Dios, declara anatema a quien lo niega. Es decir, los dogmas son la respuesta de autoridad de la Iglesia contra el adopcionismo que apelaba a un monoteísmo absoluto y que interpreta a Jesús y su filiación como adopción y no como verdadera divinidad. Es el freno al arrianismo que consideraba a Jesús como una divinidad inferior, pues Dios no puede sufrir (Ramos, 2008) (Drobner, 2001). Es la lucha contra los docetas, los apolinaristas y los monofisitas. Mientras los docetas negaban la materialidad del cuerpo para salvaguardar la divinidad de Jesús, los apolinaristas defendían la corporalidad humana de Jesús a costa de negar su psicología humana y -por su parte- los monofisitas defendían que Jesús era verdadero hombre antes de la encarnación del Logos puesto que después su humanidad desaparecía a causa de la divinidad (Moingt, 1995). Así mismo, los dogmas son la defensa de Jesucristo y la posibilidad de nuestra salvación.

\section{Los dogmas cristológicos y el Jesús histórico}

Aunque el discurso conciliar mantuvo vivas las cuestiones cristológicas y el interés soteriológico, la cristología de esta época se aleja del discurso bíblico. Si la Escritura nos había presentado un Dios que lucha y se compromete apasionadamente con el ser humano, y ese pathos divino alcanza -según los 
evangelios- una radicalidad insuperable en la historia de Jesús de Nazaret; tras la influencia griega, la historia de Jesús presentada en los evangelios queda de lado (Maisch E Vögtle, 1973). Lo que emerge es la comprensión de una divinidad abstracta de tipo metafísico u ontológico. De este modo, Jesús de Nazaret queda invisibilizado.

Para no arriesgar la figura de Jesús como divinidad y no afectar al monoteísmo judío, la Iglesia se vio en la necesidad de transformar el discurso hacia un monoteísmo relativo (trinitario). Esta transición permitió que se pase del carácter mesiánico del Jesús histórico al Logos preexistente. Esto trajo serias consecuencias: la divinidad se explica sin la humanidad de Jesús, el discurso se volvió más racional y argumentativo y se distanció del relato evangélico (Moingt, 1995). Puesto que Jesucristo quedaba como totalmente definido, el discurso se petrifica y la Iglesia y la teología se dedican solamente a explicar, repetir, imponer y preservar lo dicho. Por un lado, se deja de lado la experiencia histórica de quienes conocieron de cerca a Jesús, y por otro se hace caso omiso de las nuevas experiencias. Esto hará que, con el paso del tiempo el discurso quede desfasado, poco comprensible y para algunos, poco creíble.

El alejamiento que se produjo entre el discurso y el Jesús de la historia se vio ya presente en Nicea. Si antes se decía que Jesucristo es Hijo de Dios y Señor, ahora se dice que "el Hijo de Dios es Jesús, pues se ha hecho hombre y se ha manifestado como Jesucristo" (Moingt, 1995). Aunque, más tarde, en Constantinopla hubo un ligero intento de retomar la historicidad de Jesús, el concilio siguió afirmando la coeternidad del Hijo con el Padre. Es más, al afirmar que Jesús es el "engendrado del Padre antes de todos los siglos", estaba afirmando su eternidad que era lo propio de la naturaleza divina; es decir, el Hijo quedaba separado de todo lo creado. Si bien es cierto que la intención de Constantinopla no era demostrar la divinidad del Hijo sino la identidad de su naturaleza y su igualdad con el Padre, su pretensión termina por echar a perder su esfuerzo por recuperar la historicidad que se dejó de lado en Nicea, al decir que el Hijo "bajó de los cielos" (Moingt, 1995). Es decir, la divinidad eterna del Hijo termina venciendo al Jesús de la historia.

También Éfeso (431 d.C.) mostró una ligera vuelta al Jesús humano y con esto hizo que se impusiera la idea de la unidad de Cristo. Ante la negación de Nestorio de que el Hijo de Dios no es nacido de una mujer en el tiempo, sino que en María se engendró el hombre en quien el Verbo se hizo carne (Moingt, 1995) (separó al Verbo del hombre, lo humano de lo divino), Cirilo afirmó que María es la "engendradora de Dios" (theotokos). O sea que Jesucristo y el Hijo son uno solo y que Dios nos salvó por su Hijo, quien se encarnó y en quien la Iglesia pide creer. Con la expresión "hecho hombre" de Nicea, expresa que el Hijo se humanizó y se hizo semejante a los hombres (Flp 2,6-7); que no sólo ha asumido la naturaleza humana, sino que la ha hecho suya, como suya es su naturaleza divina. Lo que intenta Cirilo es no separar las naturalezas, sabe que en ella se juega nuestra salvación.

Este intento de retornar a la historia se vuelve a perder en el concilio de Calcedonia (451 d.C.), donde lo que prevalece es el carácter soteriológico. El problema del pensamiento dialéctico expresado en "distinguir sin dividir, unir sin confundir" (Moingt, 1995, pág. 130) las dos naturalezas de Cristo está latente. Mientras unos siguen defendiendo la unidad de las naturalezas, otros tienden a separarlas para que la 
humanidad no deteriore la divinidad del Verbo. El olvido de la historia se expresa ya en el texto de convocatoria al Concilio que emite el papa León. Parte del texto dice: "Cada singularidad [formal hace lo que le es propio en comunión con la otra: el Verbo realiza lo que depende del Verbo, la carne paga lo que incumbe a la carne. Uno de los dos brilla por los milagros, el otro sucumbe a los ultrajes..." (Moingt, 1995, pág. 144).

Como vemos, este texto pre-conciliar afirma las dos naturalezas, pero cada una tiene su papel y no hay comunicación entre ellas.

En definitiva, la cristología conciliar -irónicamente marcada por la experiencia histórica del momento- dejó de lado la historia de Jesús, y puso su interés en una salvación radicalmente trascendente (una salvación después de la muerte), individual (perdón de los pecados) y espiritual (inmortalidad), que formula como anhelo de "deificación": como divinización y participación en la naturaleza divina. Por eso, ante la pregunta "y vosotros, ċuién decís que soy?", responderá: verdadero Dios y verdadero hombre. En otras palabras, la divinidad de Jesús se convertía en la garantía y posibilidad de nuestra salvación. Y puesto que ya no importa tanto el Jesús de la historia, el discurso acerca de la identidad divino-humana de Jesús que emerge será de tipo nocional, especulativo y abstracto (Johnson, 2003) (Tamayo, 2005), y poco experiencial e histórico.

\section{La renovación cristológica del siglo $\mathrm{XX}$}

El siglo XX trajo muchos cambios en el discurso cristológico. Bajo el afán de que Jesucristo sea mejor comprendido, reavivó las cuestiones cristológicas. Su motivación la halló en la llamada vuelta al sujeto, a la persona humana. Así, la experiencia se convierte en medio de conocimiento. Otro motivo fue la experiencia de negatividad ante el sufrimiento de las personas. También el descubrimiento de la pequeñez del mundo y la interconectividad en la que vive (Johnson, 2003). Contribuyó también el darse cuenta de que la teología ya no decía nada al mundo de hoy. Todo esto permitió que la experiencia cristiana de la salvación se visualice ahora como la realización humana plena y la desaparición del sufrimiento que deshumaniza. Esto hace que emerja un antropocentrismo cultural y la fe cristológica se exprese en fórmulas antropológicas como "la humanidad nueva" (J. I. González Faus), Jesús "el hombre libre" (C. Duquoc), "el hombre para los demás" (D. Bonhoeffer), etc. Esta antropología crística hará que, en las teologías contextuales, el nuevo horizonte salvífico se vea presente en la perspectiva política y liberadora y se exprese como emancipación, inclusión, justicia, etc. Desde este horizonte, la respuesta cristológica será la confesión del Cristo liberador, Justicia de Dios, Emancipador de la mujer, etc. Veamos a grandes rasgos este proceso cristológico que mantiene la expectativa salvífica, reintroduce la experiencia de fe como herramienta teológica (la historia actual) y recupera la historia (la de Jesús y de quienes le conocieron).

\section{Análisis cristológico a la luz de la modernidad}

El análisis de los dogmas en esta época permitió ver la existencia de un docetismo latente (Vitoria, 1986) producido por el olvido del Jesús humano. Descubrieron que Calcedonia (s. V) no tenía problemas en la definición de una naturaleza humana y otra divina que confluyen en una sola persona, sino en su comprensión en los tiempos actuales. Descubrieron que el problema estaba en las categorías usadas 
("naturaleza", "persona" e "hypostasis"), pues ya no dicen nada al presente. Ante esta situación, la cristología tiene la hábil intuición de volver la mirada a la humanidad de Jesús para repensar desde allí a Jesucristo. Sin negar la divinidad que se afirma en los dogmas, buscan una nueva forma de expresarla a partir de lo humano de Jesús. Intentan percibir la divinidad de Jesús no por encima o a costa de su humanidad, sino en ella misma.

Así, la cristología unirá el dogma con la antropología y la existencia humana analizada. El resultado será el nacimiento de la teología trascendental y se dejará de lado la filosofía escolástica que definía a la persona como "sustancia individual de naturaleza racional" (Vitoria F. , 1986). La pretensión era recuperar el significado del misterio humano de Jesús y el nuestro ${ }^{3}$, para luego entender el misterio divino en Jesús, al que estamos llamados mujeres y hombres. La idea que subyace es que la naturaleza humana está hecha hacia lo infinito y se define y desarrolla en tanto tiende a la naturaleza divina (Rahner, 1979). Así, mientras más humanos somos, Dios se hace más presente en nuestras vidas. Por tanto, si Jesús estuvo unido a Dios mucho más que nosotros, Jesús es profunda y plenamente humano; y, como verdaderamente humano, es Dios con nosotros. Con esto, la divinidad de Jesús quedaba afirmada desde su verdadera humanidad (Vitoria F. ). Por tanto, decir que Jesús es Dios no significa negar su humanidad sino afirmarla en plenitud.

\section{Replanteamiento hermenéutico de la cristología}

El análisis de la situación de la cristología condujo hacia un replanteamiento en la hermenéutica cristológica al interpretar la divinidad de Jesús. Cambios que apelan a lo humano de Jesús, a la experiencia histórica del pasado cristiano, a la historia concreta y contextualizada de hoy y al anhelo de alcanzar la dignidad humana plena en la historia entendida como la salvación querida por Dios para la humanidad. Veamos brevemente estos cambios hermenéuticos en la cristología.

\section{a. La unidad intrínseca entre cristología y soteriología}

Las cristologías se afanan por recuperar la unidad intrínseca entre Cristología y Soteriología, ambas estaban latentes, pero por separado (Grillmeier, 1976). La soteriología sigue siendo el horizonte movilizador de la cristología para presentar una cristología novedosa y dar razón de cómo, en circunstancias actuales y diferentes, Jesús sigue salvando.

\section{b. La cristología y la modernidad}

Otros discursos se desarrollan en el horizonte de la modernidad y se van haciendo plurales por diversos motivos (Vilanova, 1992): por la ilustración, el desafío de la emancipación, el desafío del sufrimiento (cómo pensar a Dios después de Auschwitz y desde Ayacucho (Gutiérrez, 1988)). Algunas cristologías responderán de manera formal y abstracta (W. Kasper); pero otras lo harán de una forma más histórica y contextualizada (J. Sobrino). Hay otros discursos que optan por la desmitificación del mensaje, la intención es salvar el contenido y su significación universal y permitir un discurso más acorde a la realidad y al mundo de la razón. En esta labor se sumerge, por ejemplo, W. Kasper (Kasper, 2013).

3 Elizabeth A. Johnson cita a Jean-Paul Sartre, san Agustín y Roger Rosenblatt como aquellos que han expresado simbólicamente lo que es el misterio humano. Cf., Ibíd., pp. 36-39.

Vol $19 \mathrm{~N}^{\circ} 1$ Ene. - Jun. 2020 


\section{c. Un nuevo lenguaje al nombrar a Dios y a Jesucristo}

Desde la experiencia de opresión de los pobres y las víctimas, la perspectiva salvífica entendida como humanización ya no decía nada. En este sentido, fue inevitable un cambio en el lenguaje sobre Dios y Jesucristo; sobre todo, en el lenguaje de la Cruz (Moltmann, 2010) que fue usada para legitimar la opresión de los pobres. El cambio fue posible gracias a la reinterpretación de la cruz desde la historia y a la influencia de la teología protestante, sobre todo de Kitamori, Moltmann y üngel. Desde este horizonte, se reconoció la divinidad de Jesús desde las siguientes condiciones: a) Que Dios estaba en Jesús como anonadado o negado a sí mismo (la kenosis). b) Que el Dios de Jesús no es un Dios de poder y majestad sino de amor y solidaridad (agape). c) Que la divinidad de Jesús no elimina sus rasgos humanos ni es un añadido a su humanidad, sino la máxima potenciación de su humanidad. d) Que Jesús no es Hijo de Dios además o por encima de su humanidad, sino en su misma humanidad (el segundo Adán) (González, 1983).

\section{La vuelta al Jesús histórico: una divinidad en y desde la historia}

Hay cristologías que dejan de lado el método deductivo que parte de la idea previa de la encarnación y optan por una cristología inductiva (Rahner K. , 1964). Están convencidos de que la divinidad no deben deducirla de ideas religiosas sobre Dios, sino desde la humanidad histórica de Jesús. Apelan a que la divinidad no es lo que queda en Jesús una vez se resta su humanidad, sino que se vislumbra precisamente en su aventura humana (Segundo, 1991). Es decir, la hermenéutica recupera la historia de Jesús y la experiencia como herramientas teológicas para repensar a Jesucristo.

En un primer momento (1950-1960) se aborda la cuestión de la autoconciencia y reflexionan a Jesucristo de modo descendente (el evangelio de Juan, la patrística y la cristología medieval). En una segunda fase (1960-1970) se vuelve a los relatos evangélicos para buscar rastros de la identidad de Jesús, identificar lo central de su vida, la razón del impacto que produjo, el motivo por el que se le consideró peligroso y le crucificaron, etc. Pretenden ver en qué clase de ser humano se convirtió Dios; pues si Jesús es Dios con nosotros, el relato de Jesús es la respuesta a la pregunta de quién es Dios. En un tercer momento aparece la cuestión de la justicia. En esta fase, la cristología remite al modo en que Jesús hizo palpable el Reino de Dios en el mundo y a la experiencia de los que anhelan justicia $(1970)^{4}$. En esta hermenéutica se ubican las teologías de la Liberación, que incluye las teologías feministas, negra, asiática, etc.; las cuales aparecen con un método y características diferentes a la de las teologías trascendental y narrativa. Puesto que parten de "las marcas registradas" (Vigil, 1991) propias de cada realidad concreta, se presentan como discursos contextuales y, desde la concreción histórica intentan responder a las expectativas actuales de liberación. En este sentido, la figura de Jesucristo recupera su carácter histórico-salvíficoexperiencial y universal.

Lo que vemos es que, sin cambiar la fe en Jesús, la perspectiva se ha transformado. La hermenéutica ya no tiene como horizonte la salvación comprendida como

4 Entre los teólogos que reflexionan la fe "desde el reverso de la historia" están Gustavo Gutiérrez, Leonardo Boff, Jon Sobrino, Albert Nolan, Juan Luis Segundo, Aloysius Pieris, etc. 
divinización sino como humanización plena, como el alcance de la dignidad humana en la historia y que se espera en Jesús (GS 22). No solamente porque Jesús posibilita "una inaudita" perfección humana, "sino que además es nuestra salvación" (Vitoria F. ). Así, "la recuperación del Jesús humano nos recuerda que a lo humano no se opone sólo la ausencia o merma de humanidad, sino lo inhumano" 5 (Vitoria F. , pág. 49). Ante esto, resulta necesario la presentación de Jesús como vencedor de lo que deshumaniza y como aquel donde se expresa la fidelidad a Dios, la misericordia hacia los seres humanos y la entrega de su persona en fraternidad y solidaridad. De aquí que Jesús no es únicamente presentado como humano sino también como hermano (Heb 2,11). Dicho de otra forma, la naturaleza humana de Jesús queda expresada en su entrega de sí para hacer el bien y hacerse bueno como Dios es bueno (Cf. Mc 10,18). Esto no es otra cosa que la singularidad humana de Jesús (González, 1984) y desde ella se relee la divinidad.

\section{Conclusiones}

De esta visión de la transición de la cristología y la fundamentalidad de la experiencia en la articulación del discurso, podemos concluir que:

La cristología se ha desarrollado en la historia de forma inculturada. Desde sus inicios ha estado marcada o condicionada por la cultura en la que se ha forjado. Ante tales condicionamientos, tanto la cristología evangélica como la conciliar y los discursos cristológicos modernos, se vieron en la necesidad de transformarse para ser respuesta a los nuevos horizontes soteriológicos.

La divinidad de Jesús, en el Testamento Cristiano, intenta responder a la pregunta por quién es Jesús de Nazaret, cuál es su relación con Dios y qué tiene que ver con nosotros y nuestra salvación. En la base está la vivencia de que a Dios lo encontramos vivido y concretizado en Jesús de Nazaret, en su vida, en su palabra y comportamiento, en su muerte y resurrección (Boff, 1976).

La definición de la divinidad de Jesús en los dogmas condujo al olvido del Jesús histórico y la experiencia humana como herramienta teológica, las cuales se retoman en el siglo XX ante las exigencias de un mundo ilustrado.

La vuelta al Jesús histórico ${ }^{6}$ fue un acontecimiento transcendental para el discurso cristiano y para la vida y práctica cristiana. Permitió que las cristologías se presenten como discursos vivos, abiertos a la experiencia y a la pluralidad. En el ámbito experiencial, aprendió a partir de la vida concreta, de los sufrimientos y del deseo de liberación de los hombres y mujeres. A partir de ahora, las cristologías serán formalmente iguales, pero materialmente diferentes ${ }^{7}$ según la experiencia desde la que se forjan.

Puesto que la experiencia se presenta como un potencial enriquecedor para la teología. Se asume, como dice G. Gutiérrez, que la experiencia constituye el discurso y la herramienta primeros de

5 Ibíd., p. 49

6 La vuelta al Jesús histórico fue y es un tema difícil al no contar con una biografía de él. Pero era un tema necesario pues la divinidad anonadada se confiesa de este ser humano y no de otro. Así, lo mejor será aproximarse a él, al modo de J. Dunn. Desde la experiencia vivida y contada. Desde el "Jesús recordado" Cf. J. D. G. Dunn, Jesús recordado..., Tomo I, p. 696

7 Elementos formales tales como el diálogo con la cultura, la soteriología, la Trinidad, la Cruz, el Jesús histórico. Elementos no formales: la praxis o preteología como discurso primero, la experiencia humana. 
la teología que aparece como discurso segundo. Es en la experiencia donde la teología encuentra su validez en el acceso al conocimiento de Dios (Gutiérrez, 1990). Así, al desplazarse de un nivel meramente racional a un nivel experiencial será capaz de dar respuesta a las exigencias de la modernidad (Velasco, 2002), pues en lugar de distanciarse de la vida se acerca a ella y nace de ella con todos sus condicionamientos.

Si la experiencia de Dios está marcada por los condicionamientos históricos en los que vive el sujeto (Boff, 2001) (Torres, 1984) (Vitoria J. , 2010), la experiencia humana de Dios es una experiencia histórica; y, si esto es así, por ser histórica no es definitiva sino provisional. Por eso, el conocimiento de Dios ha de ser un aprendizaje inacabado y siempre nuevo y, por tanto, la cristología ha de mirar los signos tiempos. Así como pensó la fe desde las dos Guerras Mundiales, el Holocausto, el Gulag, etc.; y en el llamado Tercer Mundo, desde la experiencia tras el colonialismo, el Apartheid, las guerras civiles y sus masacres como las de Perú, El Salvador, Chile, Guatemala, Nicaragua, etc., la explotación laboral, la expulsión de indígenas y negros y la pobreza; hoy -además de ello- debe pensar sobre la casa común y los feminicidios, etc. Esto es importante para que la cristología, y la teología en general, escapen de "convertirse en una especie de metafísica religiosa, en una rueda que gira en el aire sin hacer marchar el carro..." (Gutiérrez, 1985, pág. 53).

\section{REFERENCIAS BIBLIOGRÁFICAS}

Barbaglio, G. (2009). Jesús de Nazaret y Pablo de Tarso. Confrontación histórica. Salamanca: Secretariado Trinitario.
Boff, L. (1976). Jesucristo el Liberador. Ensayo de cristología crítica para nuestro tiempo. Argentina: Latinoamérica Libros.

Boff, L. (2001). Gracia y experiencia humana. Madrid: Trotta.

Drobner, H. (2001). Manual de Patrología. Barcelona: Herder.

González, J. (1983). Acceso a Jesús. Ensayo de teología narrativa. Salamanca: Sígueme.

González, J. (1984). La Humanidad Nueva. Ensayo de Cristología. Santander: Sal Terrae.

Grillmeier, A. (1976). Cristología. Barcelona: Herder.

Gutiérrez, G. (1985). Beber en su propio pozo. En el itinerario espiritual de un pueblo. Salamanca: Sígueme.

Gutiérrez, G. (1988). Cómo hablar de Dios desde Ayacucho. RLT 15, pp. 233-241.

Gutiérrez, G. (1990). Teología de la Liberación. Perspectivas. Lima: CEP.

Hurtado, L. (2013). ResurrectionFaith and the 'Historical' Jesus. Bilbao: Desclée De Brouwer. Recuperado el 6 de Junio de 2015 , de http://www.brill.com/journalstudy-historical-jesus

Johnson, E. (2003). La cristología, hoy. Santander: Sal Terrae.

Käsemann, E. (1978). Ensayos exegéticos. Salamanca: Sígueme. 
Kasper, W. (2013). Jesús el Cristo. Santander: Sal Terrae.

Maisch, I., E Vögtle, A. (1973). Jesucristo. Barcelona: Herder.

Márquez, C. (2004). La importancia de los contextos: hacia una teología más experiencial y narrativa. Santander: Sal Terrae.

Moingt, J. (1995). El hombre que venía de Dios. Cristo en la historia de los hombres,. Bilbao: Desclée De Brouwer.

Moingt, J. (1995). El hombre que venía de Dios. Jesús en la historia del discurso cristiano. Bilbao: Desclée De Brouwer.

Moltmann, J. (2010). El Dios crucificado. La cruz de Cristo como base y crítica de toda teología cristiana. Salamanca: Sígueme.

Rahner, K. (1964). Escritos de Teología. Madrid: Taurus.

Rahner, k. (1979). Curso fundamental sobre la fe. Introducción al concepto de cristianismo. Barcelona: Herder.

Ramos, D. (2008). Patrología. Pamplona: EUNSA.

Schillebeeckx, E. (1981). Jesús. La historia de un viviente. Madrid: Cristiandad.

Segundo, J. (1982). El hombre de hoy ante Jesús de Nazaret. Madrid: Cristiandad.

Segundo, J. (1991). La historia perdida y recuperada de Jesús de Nazaret. Santander: Sal Terrae.
Sesboüe, B. (1995). Cristo, Señor e Hijo de Dios. Sanatander: Sal Terrae.

Sesboüe, B. (1995). Cristología y soteriología. Éfeso y Calcedonia (siglos IV y V). Salamanca: Secretariado Trinitario.

Tamayo, J. (2005). Teologías del siglo XX. Madrid: Trotta.

Theissen, G. (2009). Del Jesús histórico al Hijo de Dios del Kerigma. Selecciones de Teología, 192, pp. 271-282.

Torres, A. (1984). La experiencia de Dios. Salamanca: Sígueme.

Velasco, J. (2002). Testigos de la experiencia de la fe. Madrid: Narcea Ediciones.

Vigil, J. (1991). Descubrir la originalidad cristiana de la Iglesia Latinoamericana. Santander: Sal Terrae.

Vilanova, E. (1992). Historia de la teología. Barcelona: Herder.

Vitoria, F. (1986). ¿Todavía la divinidad de Jesús de Nazaret? Volumen I. Vitoria: ESET

Vitoria, F. (1986). ¿Todavía la salvación cristiana? Volumen II. Vitoria: ESET.

Vitoria, J. (2010). Identidad humana y experiencia cristiana de Dios. Madrid: PPC.

Fecha de recepción: $05-04-2020$

Fecha de aceptación: 15-06-2020 